\title{
Application of chelation ion chromatography to the determination of lanthanides in agriculture
}

\author{
Haitao Lu ${ }^{\text {a }}$, Shifen Mou ${ }^{\text {b.*, }}$ Yan Yan ${ }^{b}$, Feng Liu ${ }^{a}$, Kean Li ${ }^{\text {a }}$, Shenyang Tong a , \\ J.M. Riviello ${ }^{\mathrm{c}}$ \\ "College of Chemistry and Molecular Engineering, Peking University, Beijing 100871, China \\ ${ }^{b}$ Research Center for Eco-Environmental Sciences, Academia Sinica, P.O. Box 2871, Beijing 100085, China \\ ¿Dionex Corporation, Sunnvvale, CA 94086, USA
}

Received 13 December 1996; received in revised form 18 March 1997: accepted 7 April 1997

\begin{abstract}
Lanthanides are widely present in soil and plant. In this paper, it is the first time that chelation ion chromatography is applied to analyse lanthanides in a series of samples in agriculture. This technique can eliminate bulk quantity of alkali, alkaline earth metals on chelating concentrator column (MetPac CC-1) and eliminate transition metals on cation exchange column (TMC-1) from complex matrices with ammonium acetate buffer while lanthanides are concentrated. It is shown to be capable of separating and determining all lanthanides on mixed-bed ion exchange column (CS5) in a wide variety of sample types with high accuracy. Elution is carried out with a concentration gradient of oxalic acid (Ox) and diglycolic acid (DGA), coupled with post-column spectrophotometric detection with 4-(2-pyridylazo)resorcinol (PAR) at $520 \mathrm{~nm}$. It can determined $\mathrm{ng} \mathrm{ml}^{-1}$ scales of lanthanides. The whole run time after sample injection is about $55 \mathrm{~min}$. (O) 1997 Elsevier Science B.V.
\end{abstract}

Keywords: Lanthanide; Chelation ion chromatography; On-line sample pretreatment; Complex matrix

\section{Introduction}

With rapid development of lanthanides production and their widespread application in agriculture, people are even more interested in their effect to human body, environment and yield of crops. It has been reported that lanthanides have

* Corresponding author. less toxicity for human body and environment [1]. When proper concentration of lanthanides is exerted to soil, they can stimulate the growth of plant and improve the yield of crops [2-5]. So, it is important to analyse the content of lanthanides in many fields. However, instrumentation commonly used for lanthanide analysis is relatively expensive and requires skilled operators. Moreover, when matrix concentration is very high, it is required to remove the matrix previously. 
Heberling et al. [6] has successfully separated and determined transition and lanthanide metals in synthetic solution by utilizing a conventional mixed-bed ion exchange column (CS5 column) and a concentration gradient of oxalic acid and diglycolic acid. However, this method could only be used in the samples which had same magnitude level of lanthanides and interferences [7]. Cassidy [8] has shown that high performance liquid chromatography (HPLC) with on-line post-column derivitization could be applied to analyse lanthanides in solution. This method employs a mixture of hydrophobic ion and a complexing eluent to provide rapid separation of lanthanides on ODS column. Al-Shawi et al [9] has reported that the alkali, alkaline earth and transition metals interferences could be eliminated by using Arsenazo III as the derivatizing agent. However, when the content of lanthanides are very low, the samples required to be concentrated. At this time, the concentrated interferences will overload the analytical column. Thus, all these techniques can not be used to real complex samples which contain bulk quantity of alkali, alkaline earth, transition metals and low content of lanthanides. The complex matrices interfere with the separation and determination of trace lanthanides. They must be removed prior to analysis.

Chelation ion chromatography is the new technique which combines on-line analyte concentration and matrix elimination with analytical separation [10-14]. Due to high selectivities of iminodiacetate-based resins towards transition metals and property of the complexes to be kinetically labile, it has been widely used for enrichment of trace lanthanides from complex matrices while alkali, alkaline earth metals are eliminated [15-18]. The sulfonated cation exchanger will eliminate iron, aluminum and other transition metals prior to ion chromatography separation. Chelation ion chromatography is one of the most effective methods which are capable of separating individual lanthanides in complex matrices. In this paper, the method has been systematically applied to determine lanthanides in rare earth fertilizer, soil, the root, stem and leaf of paddy rice.

\section{Experimental}

\subsection{Instrumentation}

Chromatographic analyses were carried out by using a metal-free Dionex DX-300 ion chromatography (Dionex Corp., Sunnyvale, CA, U.S.A) equipped with two advanced gradient pumps (AGP), a MetPac CC-1 column $(50 \times 4$ $\mathrm{mm}$, I.D. packed with styrene-based macroporous $12 \%$ cross-linked iminodicacetate-functionalized chelating resin, the particle was $20 \mu \mathrm{m}$ and the capacity of resin was about 0.9 mequiv.), a TMC1 concentrator column $(25 \times 3 \mathrm{~mm}$, I.D. containing fully sulfonated PS-DVB cation-exchange resin with high capacity 2.2 mequiv.), an IonPac CG5 Guard column and an IonPac CS5 analytical column $(250 \times 4.6 \mathrm{~mm}$, I.D., $13 \mu \mathrm{m}$ bead diameter polystyrene divinylbenzene functionalized with both quaternary ammonium and sulfonate functional groups), a $3.66 \mathrm{ml}$ injection loop and a Dionex variable wavelength detector with a post-column reactor. The MetPac CC-1 and TMC-1 column were used for sample pretreatment. Lanthanides separation was performed on the IonPac CS5 column.

The column was kept at ambient temperature during chromatographic experiment.

Data collection and operation of all components in the system were controlled by Dionex AI-450 chromatographic software interfaced via an ACI-2 advanced computer interface to an AST Power Premium 3/33 computer.

\subsection{Chemicals and reagents}

Ammonia solution, glacial acetic acid, hydrochloric acid, nitric acid, ammonium acetate, ethanol, lithium chloride and lithium hydroxide monohydrate were of analytical-reagent grade reagents (Peking Chemical Works, Peking, China), perchloric acid, hydrofluoric acid, oxalic acid dehydrate (Ox) and 4-(2-pyridylazo)resorcinol (PAR) were of guaranteed-reagent grade reagents (Peking Chemical Works, Peking, China), pyridine-2,6-dicarboxylic acid (PDCA) was of chromatographic grade reagent (Aldrich, USA), diglycolic acid (DGA) was of chromatographic grade reagent (Fluka). 
Working standard solutions were prepared daily by standards $\left(1000 \mu \mathrm{g} \mathrm{ml}^{-1}\right)$ which were obtained from National Research Centre for Certified Reference (China).

The eluted lanthanides were detected after postcolumn reaction with PAR $(0.8 \mathrm{mM}, 1.0 \mathrm{M}$ glacial acetic acid and $3.0 \mathrm{M} \mathrm{NH}_{3}$ ) at $520 \mathrm{~nm}$. Flow-rate was $0.7 \mathrm{ml} \mathrm{min}{ }^{-1}$.

All solutions were prepared with pretreated water which was purified with a Milli-Q system ( > $18 \mathrm{M} \Omega$, Millipore. Waters Chromatography Devision, Oslo, Norway).

\subsection{Samples and sample preparation}

Samples used in this study were "Changle' rare earth fertilizer, soil, the root, stem and leaf of paddy rice (Chinese Science and Technology University).

Rare earth fertilizer sample: It was dissolved and diluted directly by $0.1 \mathrm{M} \mathrm{HNO}_{3}$.

Root, stem, leaf and soil samples: $0.3 \mathrm{~g}$ of powdered sample was weighted respectively. It was added into a closed polytetrafluoroethyene (PTFE) beaker and wetted with a small amount of water, $5 \mathrm{ml}$ of concentrated nitric acid was added and heated nearly to dryness. Then $20 \mathrm{ml}$ of $50 \%(\mathrm{w} / \mathrm{w})$ hydrofluoric acid was added and heated to dryness. Furthermore, $5 \mathrm{ml}$ of $60 \%$ $(\mathrm{w} / \mathrm{w})$ perchloric acid was added to the residue and heated until white fume of perchloric acid appeared. After standing cool, $2 \mathrm{ml}$ of concentrated nitric acid was added and evaporated to dryness again. Finally, the residue was dissolved to $25 \mathrm{ml}$ with $0.1 \mathrm{M} \mathrm{HNO}_{3}$.

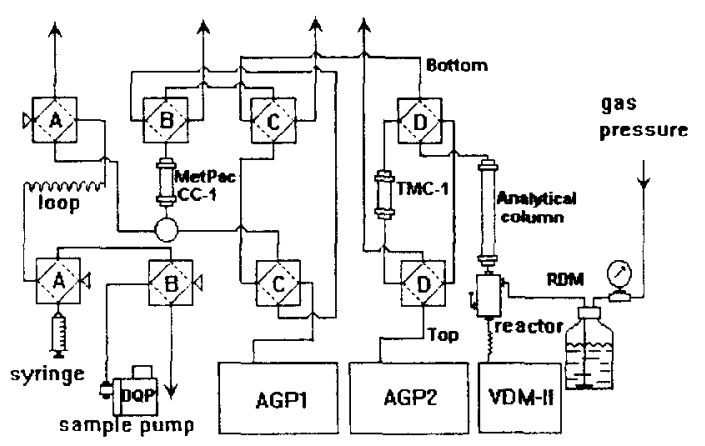

Fig. 1. Scheme of chelation ion chromatography system.

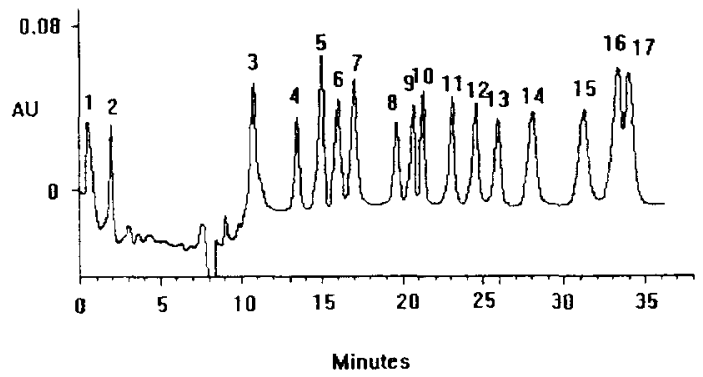

Fig. 2. Chromatogram of lanthanides in synthetic standard solution. Chromatographic conditions: Separator column: Ion-

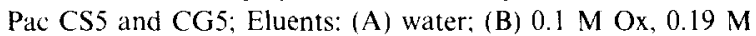
LiOH: (C) $0.1 \mathrm{M}$ DGA, $0.19 \mathrm{M} \mathrm{LiOH;} \mathrm{(D)} 0.006 \mathrm{M}$ PDCA, $0.01 \mathrm{M} \mathrm{LiOH}$ and $0.05 \mathrm{M} \mathrm{LiCl}$; Gradient: $100 \% \mathrm{D}$ for $1 \mathrm{~min}$, then $100 \%$ A for $3 \mathrm{~min}$, then $40 \%$ A, $60 \%$ B to $30 \%$ A, $70 \%$ B in $5 \mathrm{~min}$, then to $59 \% \mathrm{~A}, 25 \% \mathrm{~B}, 16 \% \mathrm{C}$ in $9 \mathrm{~min}$, then to $54 \%$ A, $25 \%$ B, $21 \%$ C in $10 \mathrm{~min}$, then to $54 \% \mathrm{~A}, 20 \% \mathrm{~B}, 26 \% \mathrm{C}$ in

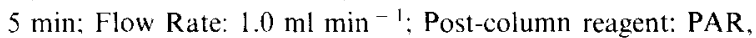
$0.7 \mathrm{ml} \mathrm{min}{ }^{-1}$, Detection $i=520 \mathrm{~nm}$. Peaks: 1 and 2 systemic peaks, $3=\mathrm{Zn}, 4=\mathrm{La}\left(240 \mathrm{ng} \mathrm{ml}^{-1}\right), 5=\mathrm{Ce}\left(200 \mathrm{ng} \mathrm{ml}^{-1}\right)$, $6=\operatorname{Pr}\left(96 \mathrm{ng} \mathrm{ml}{ }^{-1}\right), 7=\mathrm{Nd}\left(96 \mathrm{ng} \mathrm{ml}{ }^{-1}\right), 8=\operatorname{Sm}(32 \mathrm{ng}$ $\left.\mathrm{ml}^{-1}\right), 9=\operatorname{Eu}\left(32 \mathrm{ng} \mathrm{m}^{-1}\right), 10=\mathrm{Gd}\left(32 \mathrm{ng} \mathrm{ml}^{-1}\right), 11=\mathrm{Tb}$ $\left(32 \mathrm{ng} \mathrm{ml}^{-1}\right), 12=$ Dy $\left(32 \mathrm{ng} \mathrm{ml}^{-1}\right), 13=$ Ho $\left(40 \mathrm{ng} \mathrm{ml}^{-1}\right)$, $14=\operatorname{Er}\left(32 \mathrm{ng} \mathrm{ml}^{-1}\right), 15=\operatorname{Tm}\left(53.3 \mathrm{ng} \mathrm{ml}^{-1}\right), 16=\mathrm{Yb}(64$ $\left.\mathrm{ng} \mathrm{ml}{ }^{-1}\right), 17=\mathrm{Lu}\left(80 \mathrm{ng} \mathrm{ml}^{-1}\right)$, Al $\left(3.0 \mathrm{mg} \mathrm{ml}^{-1}\right)$, Fe $(3.0$ $\left.\mathrm{mg} \mathrm{ml}{ }^{-1}\right), \mathrm{Ca}\left(6.0 \mathrm{mg} \mathrm{ml}^{-1}\right), \mathrm{Mg}\left(6.0 \mathrm{mg} \mathrm{m}^{-1}\right), \mathrm{Cu}, \mathrm{Ni}, \mathrm{Zn}$, Co. $\mathrm{Mn}\left(200 \mu \mathrm{g} \mathrm{ml}^{-1}\right)$, respectively.

Extracted solution from soil: $20 \mathrm{~g}$ soil was weighted and added into a $250 \mathrm{ml}$ beaker. Then, $100 \mathrm{ml}$ of $2.0 \mathrm{M} \mathrm{NaAc}-\mathrm{HAc}(\mathrm{pH} 4.8$ ) buffer was added and oscillated $(180 \mathrm{rpm})$ on an oscillator for $30 \mathrm{~min}$. Finally, the solution was filtered with double-lay filter. The filtrate was diluted to $100 \mathrm{ml}$ with buffer solution.

Before injection, each solution needed to be further diluted to a proper concentration within its linear range and filtered through a $0.45-\mu \mathrm{m}$ filter.

\subsection{Experimental procedure}

The detailed scheme of chelation ion chromatography system was shown in Fig. 1, AGPl pretreatment program was entered method file in AI-450 operating software and subsequently down loaded onto AGP1. AGP2 concentration gradient program was entered AGP2 front panel. Elution containers were pressurized with $\mathrm{N}_{2}$ to 5 
Table 1

Lanthanide analytical results of soil sample

\begin{tabular}{|c|c|c|c|c|c|}
\hline Lanthanide & $\mathrm{IC}\left(\mu \mathrm{g} \mathrm{g}^{-1}\right)$ & ICP-MS $\left(\mu \mathrm{g} \mathrm{g}^{-1}\right)$ & Spiked $\left(\mu \mathrm{g} \mathrm{g}^{-1}\right)$ & Found $\left(\mu \mathrm{g} \mathrm{g}^{-1}\right)$ & Recoveries (\%/1) \\
\hline $\mathrm{La}$ & 46.84 & 46.7 & 30.2 & 77.76 & 102.4 \\
\hline $\mathrm{Ce}$ & 87.52 & 85.4 & 24.0 & 110.2 & 94.6 \\
\hline $\operatorname{Pr}$ & 10.38 & 9.4 & 13.2 & 24.66 & 108.2 \\
\hline $\mathrm{Nd}$ & 39.21 & 40.1 & 11.5 & 51.3 & 105.1 \\
\hline $\mathrm{Sm}$ & 6.87 & 7.5 & 4.2 & 11.32 & 106 \\
\hline $\mathrm{Eu}$ & 1.49 & 1.36 & 5.8 & 6.95 & 94.1 \\
\hline Gd & 6.09 & 6.1 & 5.0 & 11.32 & 104.6 \\
\hline $\mathrm{Tb}$ & 1.01 & 0.88 & 4.6 & 5.83 & 104.8 \\
\hline Dy & 5.82 & 5.65 & 4.4 & 10.04 & 96 \\
\hline $\mathrm{Ho}+\mathrm{Y}$ & 71.4 & $1.02+29$ & 3.7 & 74.8 & 92.1 \\
\hline $\mathrm{Er}$ & 3.2 & 3.35 & 5.5 & 8.59 & 98 \\
\hline $\mathrm{Tm}$ & 0.5 & 0.45 & 7.6 & 8.4 & 104 \\
\hline $\mathrm{Yb}$ & 3.28 & 3.01 & 7.6 & 11.47 & 107.8 \\
\hline $\mathrm{Lu}$ & 0.4 & 0.44 & 11.4 & 12.61 & 107.1 \\
\hline
\end{tabular}

$n=5$.

psi. When operation started, the sample in injection loop was flushed by $0.1 \mathrm{M} \mathrm{HNO}_{3}$ from sample pump to mixing tee where it was buffered with ammonium acetate solution and entered MetPac CC-1 column. All anions and monovalent cations could not be retained. Following, alkaline earth metals were selectively removed by ammonium acetate buffer further. Then, the residual metals on the MetPac CC-1 column were transferred to TMC-1 column by $\mathrm{HCl} / \mathrm{EtOH}$ solution, and there rinsed by $\mathrm{Ox} / \mathrm{HNO}_{3}$ solution further. Lanthanides were quantitatively concentrated while iron, aluminum and other transition metals were eluted to the waste. Finally, after AGP1 delivered $0.1 \mathrm{M}$ ammonium nitrate to convert TMC-1 column from hydrogen form to ammonium form, AGP2 delivered PDCA to elute lanthanides from TMC-1 column to CS5 column. Following separation, the lanthanides were eluted by a concentration gradient of $O x$ and DGA detected photometrically using PAR post-column reagent at $520 \mathrm{~nm}$.

\section{Results and discussion}

\subsection{Matrix elimination and concentration}

The first matrix elimination step was performed on MetPac CC-1 column to remove alkali and alkaline earth metals from sample matrix. The MetPac CC-1 column contained macroporous iminodiacetate chelating resin which had very high affinity for transition and lanthanide metals compare to alkali and alkaline earth metals. The higher valency of the metal ion, the stronger bound metal ion was to the resin. Before sample stream passed through MetPac CC-1 column, the sample previously loaded into injection loop was flushed by acid carrier and buffered on-line with $2.0 \mathrm{M}$ ammonium acetate eluent in the $\mathrm{pH}$ range of 5-6. All anions and monovalent cations were not retained. By using $2 \mathrm{M}$ ammonium acetate eluent further, alkaline earth metals could be selectively eluted while most transition and all lanthanide metals remained quantitatively bound to the column. Ten mg of Ca could be eluted completely within $5 \mathrm{ml}$ eluent. The other alkaline earth metals had the same results. Changes of flow-rate from 1 to $3 \mathrm{ml} \mathrm{min}{ }^{-1}$ did not influence the recoveries of retained metals. Then, the remaining ammonium acetate on MetPac CC-1 column was removed by $0.1 \mathrm{M}$ ammonium nitrate, otherwise, the high concentration of ammonium acetate would crystallize in it.

The selective elimination process proceeded further was to remove the bulk quantity of iron, aluminum and other transition metals on high 
capacity TMC-1 concentrator column. It contained fully sulfonated cation exchange resin which had high affinity for multivalent cations. The selective matrix removal was based upon the stable metal chloride complexes in a mixture of $4.0 \mathrm{M}$ hydrochloric acid $65 \%$ ethanol eluent. The mixture not only promoted the formation of relatively stable metal chloride complexes, it also decreased the distribution coefficient of the metal complexes on cation exchange resin [10]. It was the effect of high concentration of ethanol that water molecules around the metals were reduced, the forces binding the coordinated hydrated shell and the size of the outer hydration cloud were decreased. As a result, the transition metal chloride complexes formed in the mixture were more stable than that in aqueous system. On the other hand, lanthanides formed less stable metal chloride complexes. Thus, the relatively stable metal chloride complexes of transition metals were selectively removed from TMC-1 column while lanthanides were quantitatively retained and concentrated. Ten $\mathrm{mg}$ of transition metals could be eluted within $6 \mathrm{ml}$ eluent. But there were still partial iron and aluminum on the column. Some of them were from the matrix that could not be eluted completely and the others were introduced by eluents. So, they were eluted further by $1.0 \mathrm{M} \mathrm{Ox} / 0.1 \mathrm{M}$ $\mathrm{HNO}_{3}$ eluent, which existed as $\mathrm{Fe}(\mathrm{Ox})_{3}^{3}$ and $\mathrm{Al}(\mathrm{Ox})_{3}^{3-}$. The acidity of this eluent $\left(\mathrm{pH}^{1-2}\right)$ was very important, or else, the lanthanides would be eluted as $\mathrm{La}(\mathrm{Ox})_{3}^{3--}$. Before the lanthanides were eluted to CS5 column, TMC-1 column must be converted from hydrogen form to ammonium form, otherwise the remaining matrices would interfere the separation of lanthanides. Sometimes, they could overlap the peak of $\mathrm{La}$.

\subsection{Chromatographic separation}

The separation of lanthanides was accomplished by anion exchange of lanthanide-chelator complexes on mixed-bed IonPac CS5 analysis column. Before starting each analysis, the separation required column equilibration with PDCA eluent. The analytical system equilibrated while sample pretreatment steps were being performed. In this separation, PDCA eluent had two kinds of effects. On one hand, it removed metal contaminants introduced by $\mathrm{Ox}$ and DGA eluents from the analysis column, such as iron and aluminum, which existed as $\mathrm{Fe}(\mathrm{Ox})_{3}^{3-}$ and $\mathrm{Al}(\mathrm{Ox})_{3}^{3-}$ bound strongly by the anion exchange sites of the resin. On the other hand, when TMC-1 column was placed on-line with analysis column, PDCA eluted concentrated lanthanides and trace transition metals from TMC-1 column as Metal-PDCA complexes to IonPac CS5 column. Lanthanides formed stable trivalent anionic complexes. Transition metals formed stable divalent anionic complexes which were eluted before lanthanides. But the remaining PDCA on CS5 column would affect the separation and detection of lanthanides. Thus, it must be removed by DI water first. Then lanthanides were separated by using concentration of gradient Ox and DGA eluents. The separation was based on the stability of lanthanidechelator complexes, the smallest ions formed the strongest complexes and were the least negatively changed. Therefore, when lanthanides was separated by anion exchange with Ox and DGA eluents, the eluent order was from $\mathrm{La}$ to $\mathrm{Lu}$.

A series of concentration gradient separating conditions had been tested. From these experiments, an optimum condition was chosen. A typical chromatogram of synthetic standard solution was illustrated in Fig. 2. It was shown that the individual lanthanides peaks were well separated. Although there were bulk quantity of alkali metals, alkaline earth metals, aluminum, iron and other transition metals in the solution, they could not affect the separation and determination of lanthanides.

\subsection{Accuracy and detection limit}

Under the optimized program, it produced much sharper peaks with good peak separation and excellent calibration curves. All lanthanides had good linearities whose correlation coefficients were greater than 0.998 in the range $15-400 \mathrm{ng}$ 

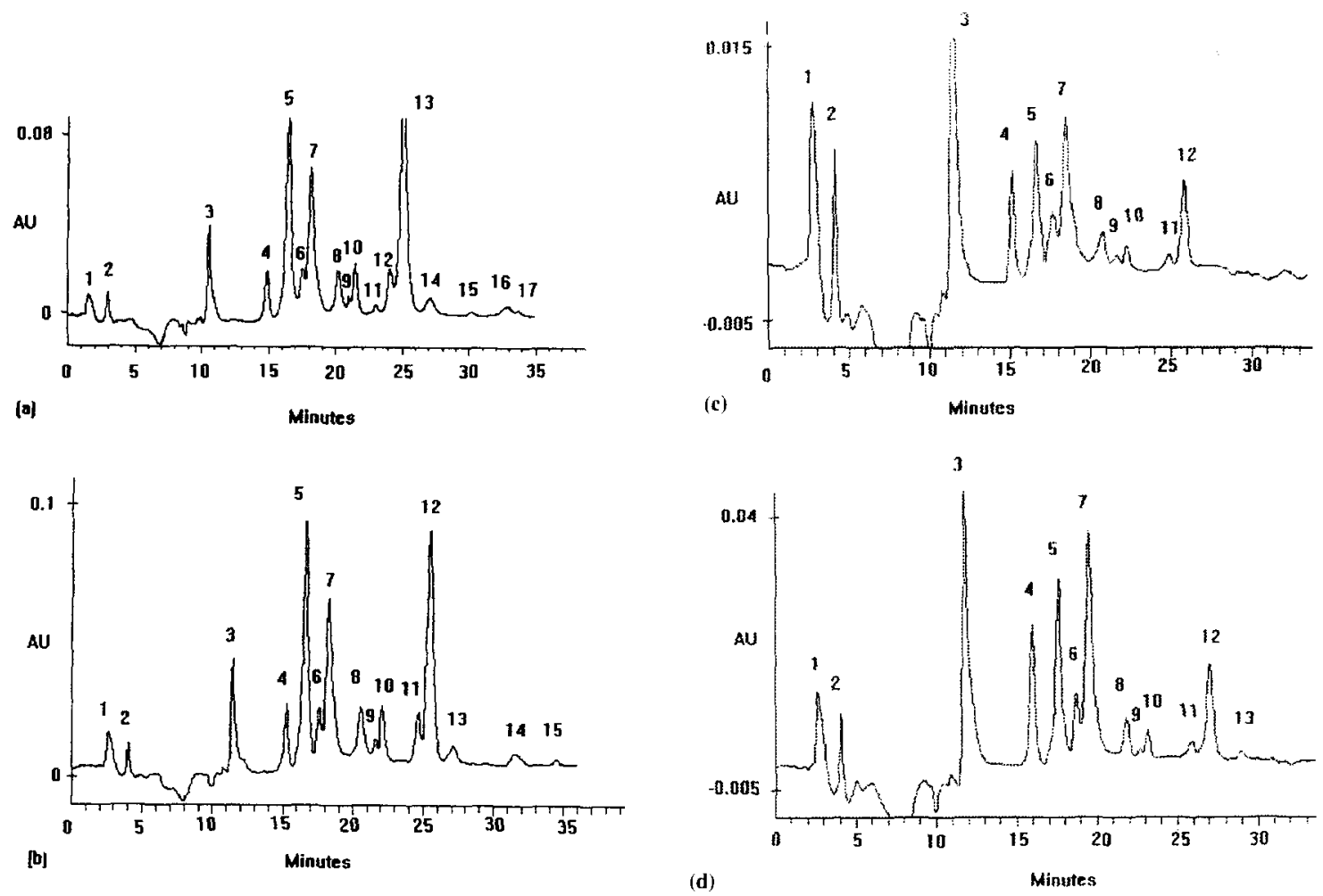

Fig. 3. Chromatogram of lanthanides in a series of samples. (a) Soil, (b) root, (c) stem, (d) leaf. Similar chromatographic conditions to Fig. 2. Peaks: 1 and 2 systemic peaks, $3=\mathrm{Zn}, 4=\mathrm{La}, 5=\mathrm{Ce}, 6=\mathrm{Pr}, 7=\mathrm{Nd}, 8=\mathrm{Sm}, 9=\mathrm{Eu}, 10=\mathrm{Gd}, 11=\mathrm{Tb}, 12=\mathrm{Dy}$, $13=\mathrm{Ho}, 14=\mathrm{Er}, 15=\mathrm{Tm}, 16=\mathrm{Yb}, 17=\mathrm{Lu}$

$\mathrm{ml}^{-1}$ for $\mathrm{La}, \mathrm{Ce}, 6-120 \mathrm{ng} \mathrm{ml}^{-1}$ for $\mathrm{Pr}, \mathrm{Nd}, \mathrm{Yb}$, $\mathrm{Lu}, 2-64 \mathrm{ng} \mathrm{m}^{-1}$ for Sm, Eu, Gd, Tb, Dy, Ho and $3-100 \mathrm{ng} \mathrm{ml}^{-1}$ for Er, Tm. The R.S.D. based on $>10 \times$ detection limits concentration $(n=7)$ was found to be in the range of $1.8-5.5 \%$. It was clear from Fig. 2 that the method sensitivity was different among individual lanthanides. The absorbance of light-lanthanides was less than the middle and heavy-lanthanides. The detection limits (signal-to-noise ratio $3: 1$ ) of this method from La to Lu were 6.7, 2.7, 1.7, 1.3, 0.7, 0.7, 0.6, 0.7, $0.6,0.7,0.9,1.3,1.5$, and $1.9 \mathrm{ng} \mathrm{ml}^{-1}$, respectively.

\subsection{Analysis of sample}

As a validation of the analytical technique, soil sample whose lanthanides had been determined previously by ICP-MS was analyzed.. Table 1 showed the comparison. They were averages of three totally independent analyses involving sample digestion and chelation ion chromatography procedure. They were obtained based on the system calibration with our standards. It was found that the IC values were in good agreement with ICP-MS values. All of them had good spiked recoveries. Because of the appreciable overlap between Ho and Y peaks, it was difficult to obtain reliable values for them. Furthermore, it could be seem from Fig. 3(a) that separations between $\mathrm{Pr}$ and $\mathrm{Nd}, \mathrm{Eu}$ and $\mathrm{Gd}$ were not well. It was because the concentration of $\mathrm{Nd}$ and $\mathrm{Gd}$ were bigger than that of Pr and Eu, respectively. So, the peaks of $\mathrm{Nd}$ and Gd overlapped partial peaks of $\mathrm{Pr}$ and $\mathrm{Eu}$, respectively. Fig. 3(a) also showed that the interference which had been eliminated during the sample pretreatment did not affect the separation and determination any more. 
Table 2

Lanthanides analytical results of fertilizer, extracted solution from soil, the root, stem and leaf of paddy rice

\begin{tabular}{|c|c|c|c|c|c|}
\hline Lanthanide & Fertilizer $\left(\mathrm{mg} \mathrm{g}^{-1}\right)$ & Extracted solution $\left(\mu \mathrm{g} \mathrm{g}^{-1}\right)$ & $\operatorname{Root}\left(\mu \mathrm{g} \mathrm{g}^{-1}\right)$ & Stem $\left(\mu \mathrm{g} \mathrm{g}^{-1}\right)$ & Leaf $\left(\mu g \mathrm{~g}^{-1}\right)$ \\
\hline $\mathrm{La}$ & 125 & 1.427 & 12.1 & 3.81 & 10.0 \\
\hline $\mathrm{Ce}$ & 38.6 & 2.324 & 21.9 & 1.70 & 6.01 \\
\hline $\operatorname{Pr}$ & 17.3 & 0.347 & 2.21 & 0.405 & 1.36 \\
\hline $\mathrm{Nd}$ & 41.2 & 1.671 & 8.86 & 1.36 & 4.49 \\
\hline $\mathrm{Sm}$ & 2.67 & 0.407 & 1.56 & 0.148 & 0.412 \\
\hline $\mathrm{Eu}$ & 0.37 & 0.104 & 0.276 & 0.029 & 0.101 \\
\hline $\mathrm{Gd}$ & 0.59 & 0.498 & 1.43 & 0.057 & 0.25 \\
\hline $\mathrm{Tb}$ & N.D. & 0.071 & 0.195 & 0.02 & 0.0374 \\
\hline Dy & N.D. & 0.353 & 1.39 & 0.044 & 0.148 \\
\hline Ho & N.D. & 2.44 & 7.72 & 0.318 & 1.087 \\
\hline $\mathrm{Er}$ & N.D. & 0.142 & 0.80 & N.D. & 0.107 \\
\hline $\mathrm{Tm}$ & N.D. & 0.0344 & 0.10 & N.D. & N.D. \\
\hline $\mathrm{Yb}$ & N.D. & 0.095 & 0.696 & N.D. & N.D. \\
\hline $\mathrm{Lu}$ & N.D. & 0.028 & N.D. & N.D. & N.D. \\
\hline
\end{tabular}

N.D., not detected.

System blanks were well below the detection limits for all lanthanides, and there was no indication of any memory effect when a blank was run immediately after a sample with high concentration of lanthanides. These results indicated that the present chelation ion chromatography system is useful for the determination of lanthanides in samples with complex matrices. One of the most important advantage of applying this method was that analytical media could be injected directly for analysis after sample digestion.

The other samples used in this study were rare earth fertilizer, extracted solution from soil, the root, stem and leaf of paddy rice which grew in the soil. Fig. 3(b)-(d) showed some of their chromatograms. It was shown from Table 2 that only dissoluble lanthanides could be absorbed, although the contents of lanthanides in soil was very high, most of them could not be absorbed by paddy rice. It was also seen from Table 2 that the content of dissoluble lanthanides extracted from soil by HAc-NaAc buffer were lower than that in soil greatly. When the dissoluble lanthanides in soil were too low, rare earth fertilizer was needed. Among the root, stem and leaf, the root could absorb and concentrate lanthanides directly from soil, therefore, the contents of lanthanides in it were the highest. The stem delivered lanthanides mainly, therefore, the contents of lanthanides in it were the lowest. Because the paddy rice had not come to its mature period, we had not the datum of grain.

The properties of lanthanides were very similar. But, there were strong light lanthanides enrichment in real samples (e.g. fertilizer, root). So, they could not be determined in a single run. In order to maintain the lanthanides concentration in analyte solution within the linear calibration range and above the detection limit of the method, it was necessary to analyse same sample in different concentration. However, some lanthanides in samples (e.g. leaf, stem) were too low to be determined. If solutions were too thick, the concentration of interference would be too high to be eliminated completely through sample pretreatment and the high concentrated lanthanides would cover the low concentrated lanthanides. All these needed to be studied further in our next work.

\section{Summary}

The on-line chelation ion chromatography technique performed reliable and accurate analyses of lanthanides in complex matrices. The sample preconcentration and matrix elimination covered a wide range of sample matrix concentration. It was 
an extremely versatile technique that the determination of lanthanides was easily adaptable to a wide variety of analytical problems in agriculture.

\section{References}

[1] G.X. Xu, Xitu, vol.2, Ch. 17, Beijing, 1995, pp. 386.

[2] P.L. Liu, J.L. Tian, Y.Q. Li, T.J. Ju, J. Chinese Rare Earth Soc. 13 (2) (1995) 155.

[3] H.Z. Liu, Y.D. Li, R. Hao, J. Chinese Rare Earth Soc. 13 (3) (1995) 283.

[4] D.R. Yan, L.D. Zhang, Y.J. Liu, Chinese Rare Earths 17 (4) (1996) 70

[5] J.T. Zhang, D.F. Cui, Chinese Rare Earths 16 (4) (1995) 60.

[6] S.S. Heberling, J.M. Riviello, S.F. Mou, A.W. Ip, Res. Dev. 29 (9) (1987) 74
[7] A.W. Al-Shawi, R. Dahl, J. Chromatogr A 671 (1994) 173.

[8] R.M. Cassidy, Chem. Geol. 67 (1988) 185.

[9] A.W. Al-Shawi, R. Dahl, Anal. Chim. Acta 333 (1996) 23.

[10] S.F. Mou, A. Sirirars, J.M. Riviello, Sepu 12 (1994) 166.

[11] A. Sirirars, H.M. Kingston, J.M. Riviello. Anal. Chem. $62(1990) 1185$

[12] J.M. Riviello, A. Siriraks, R.M. Manake, R. Roehl, U. Alforque, LC/GC 9 (1991) 704.

[13] A. Siriraks, J.M. Riviello, M.P. Harrold, Pittsburg Conf., 1992, p. 1226 (abstract).

[14] Dionex, Technical Note 27.

[15] J.P. Riley, D. Taylor, Anal. Chim. Acta 40 (1968) 479

[16] S. Hirata, K. Honda, T. Kuamamany, Anal. Chim. Acta 221 (1989) 65

[17] R.R. Greenberg, H.M. Kingston, J. Radioanal. Chem. 71 (1982) 147.

[18] Y. Liu, J.D. Ingle Jr., Anal. Chem. 61 (1989) 520. 